\title{
Voltage Sag/ Voltage Swell Compensation and Reduction Harmonic Distortion using Dynamic Voltage Restorer
}

\author{
T.Geetha Krishna ${ }^{1}$, Dr.M.Damodar Reddy ${ }^{2}$ \\ PG Student [PSOC], Department of EEE, SV University, Tirupathi, A.P ${ }^{1}$ \\ Professor, Department of EEE, SV University, Tirupathi, A.P ${ }^{2}$
}

\begin{abstract}
Power quality is one of the most important factors in the present days. Power quality problem arises due to abnormal current, voltage or frequency, which results in end user equipment failure. This paper describes the power quality problems consist of a large number of disorders such as voltage sags, swells and its effect on sophisticated loads. For solving these types of problems, custom power devices are used. Dynamic Voltage Restorer (DVR), is one of the most effective and efficient modern custom power device. This device is used in power distribution networks. By using DVR it includes lower cost, smaller size. It also gives fast dynamic response to the disturbances. The dynamic voltage restorer improves voltage waveform and ensures constant load voltage by adding compensated voltage. By finding the differences between desired and measured values, the compensating signals are generated dynamically .If there is any disturbance in the network then dynamic voltage restorer generates injected voltage. If any power quality problem arises in source side then this injected voltage can regulate the voltage at the load terminals. With derived reference load terminal voltages, the control of dynamic voltage restorer is implemented. To verify the performance of proposed system, results Matlab with its simulink and simpower system tool boxes are used.
\end{abstract}

Keywords: Dynamic Voltage Restorer, Power quality, Voltage Sag, Voltage Swell, Harmonic distortion, Matlab/Simulink.

\section{INTRODUCTION}

Ideally Power distribution systems should provide their unbalance, low flicker at the load voltage and low customers with continuous flow of energy at smooth harmonic distortion in load voltage magnitude and sinusoidal voltage and at the smaller frequency. But in duration of over voltage and under voltage within its practical power systems, particularly the distribution specified limits, acceptance of fluctuations and poor factor systems have number of non linear loads which drastically loads without significant effect on terminal voltage.

affect the quality of power supplies. The purity of the waveform is lost due to non linear loads, which leads to many power quality problems. Beside from non linear loads, both usual (eg: capacitor switching, motor starting) and unusual (eg: fault) system events could also cause power quality problems. Power quality disturbance can be defined as the deviation of the voltage and the current from its ideal waveform. In the entire system voltage sag or voltage swell may cause due to faults which occurs either at the transmission or distribution level. Voltage Sag is short duration reduction in rms voltage. Voltage Swell is the opposite of Voltage Sag. Voltage Swell which is momentary increase in voltage. Voltage Sag and Swell occurs during the duration of 0.5-30 cycles. Voltage Sag occurs at voltage of $0.1-0.9 \mathrm{pu}$ whereas Voltage Swell occurs at voltage of 1.1-1.8pu.

Voltage Sag and Swell can mitigate by different methods. Custom power devices are used for reducing Voltage Sag and Swell, this is most efficient method. The term custom powers generally refer to the use of power electronics controller in a distribution system, especially to deal with various power quality problems. Custom power assurers customers to get prespecified quality and reliability of supply. The pre specified quality may contain following specifications: no power interruption, low phase

There are various types of custom power devices used in electrical network to improve power quality problems. Each of its devices has its own advantages and disadvantages. The SVC has more advantages than the DVR, but the DVR is still preferred because the SVC has no ability to control active power flow.

Another reason include that dynamic voltage restorer has a high energy capacity compared to UPS and SMES devices. Furthermore, the dynamic voltage restorer cost is less and smaller in size when compared to the DSTATCOM and other custom power devices. Based on these reasons, the dynamic voltage restorer is widely considered as an efficient custom power device in mitigating Voltage Sag.

\section{DYNAMIC VOLTAGE RESTORER}

Dynamic Voltage Restorer is a Custom Power Device used to reduce supply side voltage disturbances. Dynamic voltage restorer also known as Static Series Compensator maintains the load voltage at a desired phase and magnitude by reducing the voltage sags/swells and voltage unbalances presented at the point of common coupling.

The power circuit of the DVR is shown in Fig. 1. 




Figure 1: Dynamic Voltage Restorer series connected Topology

The DVR consists of 6 major parts:-

a) Voltage Source Inverter (VSI):

These inverters have high current ratings and low voltage ratings as step up transformers are used to increase the injected voltage.

b) Injection Transformers:

Three single phase injection transformers are connected in star/open winding to the distribution line. These transformers can be also connected in delta/open winding. The star/open winding allows injection of positive, negative and zero sequence voltages whereas delta/open winding only allows positive and negative sequence voltage injection.

Injection transformers play a very important role in providing the maximum safety and effectiveness of the restoration scheme. It is connected in series with the distribution feeder. Its main task is to connect the Dynamic Voltage Restorer to the distribution network through the $\mathrm{HV}$-windings and transform the injected compensating voltages generated by the voltage source converters to the incoming supply voltage. It also isolates the load from the system.

c) Passive Filters:

In Dynamic Voltage Restorer passive filters are positioned at the high voltage side to filter the harmonics. When the filters are placed at the inverter side then phase angle shift may introduced which can disorder the control algorithm.

d) Energy storage:

Storage system can be used to protect susceptible production equipments from shutdowns caused by Voltage Sag. In the distribution system the Dynamic Voltage Restorer requires real power for compensation during voltage disturbances. When the voltage disturbance exists, the energy storage supplies the real power to the Dynamic Voltage Restorer. Mainly battery is used as energy storage device. Battery is responsible to supply an energy source in DC form. Some other examples of energy storage devices are dc capacitors, super capacitors, super conducting magnetic energy storage flywheels. Batteries are the common choice and can be highly efficient if a high voltage battery configuration is used. The capacity of energy storage device has a big impact on the compensation capability of the system. Compensation of real power is essential when large Voltage Sag occurs.

e) By-Pass Switch

The Dynamic Voltage Restorer will be isolated from the system by using the bypass switches if the over current on the load side exceeds a permissible limit due to short circuit on the load or large inrush current. By-pass switch provides another path for current.

f) Capacitor

To ensure stiff DC voltage input to inverter a large DC capacitor is placed in Dynamic Voltage Restorer.

\section{OPERATION OF DYNAMIC VOLTAGE RESTORER}

The schematic diagram of a DVR is shown in Figure-2. Three phase source voltages ( $\mathrm{Vsa}_{\mathrm{V} s \mathrm{~b}}$, and $\mathrm{Vsc}_{\mathrm{V}}$ ) are connected to the 3-phase critical load through series impedance ( $\mathrm{za}$, $\mathrm{Zb}, \mathrm{Zc})$ and an injection transformer in each phase. The terminal voltages $\left(\mathrm{Vta}_{\mathrm{ta}}, \mathrm{Vtb}, \mathrm{Vtc}_{\mathrm{tc}}\right.$ ) have power quality problems and the DVR injects compensating voltages $(\mathrm{vCa}, \mathrm{vCb}, \mathrm{vCc})$ through an injection transformer to get balanced and undistorted load voltages $\left(\mathrm{VLa}_{\mathrm{VLb}}, \mathrm{VLc}\right)$. The DVR is implemented using a three leg voltage source inverter with IGBTs along with a dc capacitor $\left.{ }_{(\mathrm{Cdc}}\right)$. A ripple filter ${ }_{\mathrm{Lr}}$, $\mathrm{Cr}$ ) is used to filter the switching ripple in the injected voltage. The considered load, sensitive to power quality problems is a three-phase balanced lagging power factor load. A self-supported DVR does not need any active power during steady state because the voltage injected is in quadrature with the feeder current.



Figure-2 Schematic diagram of Dynamic Voltage Restorer


Figure 3:Phasor diagram for (a)VoltageSag

(b) Voltage Swell

The DVR operation for the compensation of sag, swell in supply voltages is shown in Figure-3. Before sag the load voltages and currents are represented as $\mathrm{VL}_{\mathrm{L}}$ (pre sag) and Isa' as shown in Figure- 3(a). After the sag event, the terminal voltage $(\mathrm{vta})$ is gets lower in magnitude and lags the pre sag voltage by some angle. The DVR injects a compensating voltage $(\mathrm{vCa})$ to maintain the load voltage $(\mathrm{vL})$ at the rated magnitude. VCa has two components, $\mathrm{vCad}$ and vaq. The voltage in-phase with the current ( $\mathrm{vCad})$ is 
required to regulate the dc bus voltage and also to meet the power loss in the VSI of DVR and an injection transformer. The voltage in quadrature with the current $(\mathrm{vCaq})$ is required to regulate the load voltage $\left(\mathrm{vL}_{\mathrm{L}}\right)$ at constant magnitude. During swell event, the injected voltage $(\mathrm{vCa})$ is such that the load voltage lies on the locus of the circle as shown in Figure-3(b).

Dynamic Voltage Restorer operating states:

a) During the normal operation

Under normal working condition DVR is not injecting any voltage to the system. If the energy device is fully charged then the DVR operates in standby mode or in the selfcharging mode.

b) During a Voltage sag/swell

By supplying the real power from the energy storage device together with the reactive power, the DVR injects the difference between the pre-sag and sag voltage .

c) Fault in the downstream of the power line

In this case, by-pass switch is operated and provide alternative path for the high fault currents. If this high fault current flows through the inverter, it may damage the sensitive power electronic component.

\section{CONTROL OF DYNAMIC VOLTAGE RESTORER}

The compensation for voltage sags using a DVR can be performed by injecting/absorbing reactive power or real power. When the injected voltage is in quadrature with the current at the fundamental frequency, compensation is achieved by injecting reactive power and the DVR is selfsupported with dc bus. But, if the injected voltage is in phase with the current, DVR injects real power and hence a battery is required at the dc side of VSI. The control technique adopted should consider the limitations such as the voltage injection capability (inverter and transformer rating) and optimization of the size of energy storage .Figure-4 shows the control block of the DVR . The voltages at $\mathrm{PCC}\left(\mathrm{vv}_{\mathrm{t}}\right)$ are converted to the rotating reference frame using the abc-dqo conversion. The harmonics and the oscillatory components of voltages are eliminated using low pass filters (LPF). The components of voltages in d-axis and q-axis are,

$$
\mathrm{v}_{\mathrm{sd}}=\mathrm{v}_{\mathrm{sd}} \mathrm{dc}+\mathrm{v}_{\mathrm{sd}} \mathrm{ac} \mathrm{v}_{\mathrm{sq}}=\mathrm{v}_{\mathrm{vsq}} \mathrm{dc}+\mathrm{v}_{\mathrm{sq}} \mathrm{ac}
$$

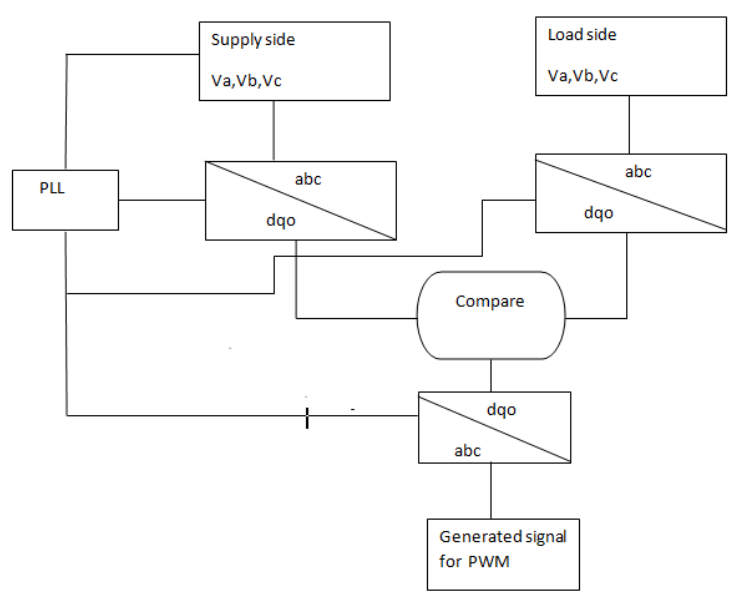

Figure 4: Control of Dynamic Voltage Restorer
The compensating strategy for compensation of voltage quality problems considers that the load terminal voltage should be of rated magnitude and undistorted.

The dqo transformation or Park's transformation [6] is used to control of DVR. The dqo method gives the sag depth and phase shift information with start and end times. The quantities are expressed as the instantaneous space vectors. Firstly convert the voltage from $a-b-c$ reference frame to d-q-o reference. For simplicity zero phase sequence components is ignored.

Illustrates a flow chart of the feed forward dqo transformation for voltage sags/swells detection. The detection is carried out in each of the three phases. The control is based on the comparison of a voltage reference and the measured terminal voltage $\left(\mathrm{va}_{\mathrm{a}}, \mathrm{vb}, \mathrm{vc}_{\mathrm{c}}\right)$. The voltage sags is detected when the supply drops below $90 \%$ of the reference value whereas voltage swells is detected when supply voltage increases up to $25 \%$ of the reference value. The error signal is used as a modulation signal that allows generating a commutation pattern for the power switches (IGBT's) constituting the voltage source converter. The commutation pattern is generated by means of the sinusoidal pulse width modulation technique (SPWM); voltages are controlled through the modulation.

The speed of the response is determined by parameters ${ }_{\mathrm{K}}$, $\mathrm{Kp}$ and $\mathrm{Kv}$. These parameters control transient as well as steady state behaviour of the filter. There exists a compromise between speed and accuracy. For large ${ }_{\mathrm{K}}$ and $\mathrm{Kp}, \mathrm{Kv}_{\mathrm{v}}$, the convergence of the estimated values to actual values is faster but the steady state misadjustment is higher. This is an inherent characteristic of an adaptive algorithm. Parameters and ought to be selected appropriately according to the application. Increasing the value of $\mathrm{K}$ increases the speed. However, it creates oscillations in the peak detection response. There is a trade-off between speed and accuracy (or smoothness). Decreasing $_{\mathrm{K}}$ and $\mathrm{Kp}_{\mathrm{Kv}}$ yields and estimation of the peak which is insensitive / robust to the undesirable variations and noise in the input signal. The presented PLL provides the following advantages online estimation of the amplitude, phase and their corresponding time derivatives of the pre-selected component of the input signal are provided.

\section{MATLAB SIMULATION}

By using the Simulink and SimPower System toolboxes in the Matlab DVR is modelled. The MATLAB model of the DVR connected system is shown in fig. below. The three-phase load is connected to the three-phrase programmable source through the DVR in order to generate sag, swell and harmonics in supply side. The considered load is a lagging power factor load. By using an injection transformer the VSI of the DVR is connected to the system. For filtering the switching ripple in the terminal voltage a ripple filter is connected across the terminals of the secondary of the transformer. Based on the transient energy requirement and the dc bus voltage the dc bus capacitor of DVR is selected. The ripple content in the dc voltage is decided by dc capacitor. The system data are given in Appendix. 
INTERNATIONAL JOURNAL OF INNOVATIVE RESEARCH IN ELECTRICAL, ELECTRONICS, INSTRUMENTATION AND CONTROL ENGINEERING

凮



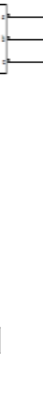
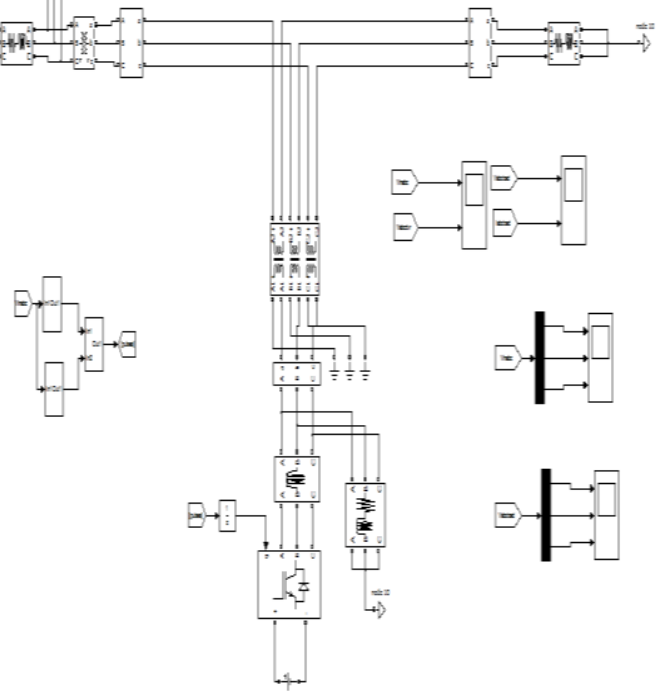

Figure5: Matlab for Dynamic Voltage Restorer connected system

\section{PERFORMANCE OF A SYSTEM}

The performance of the DVR is demonstrated for different supply voltage disturbances such as sag and swells in supply voltage. A case of Three-phase voltage sag is simulated and the results are shown in Figure-6.

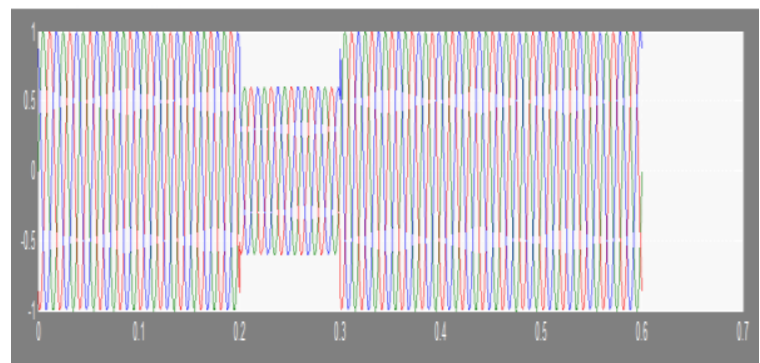

Figure 6(a): Supply Side Voltage with 50\% voltage sag

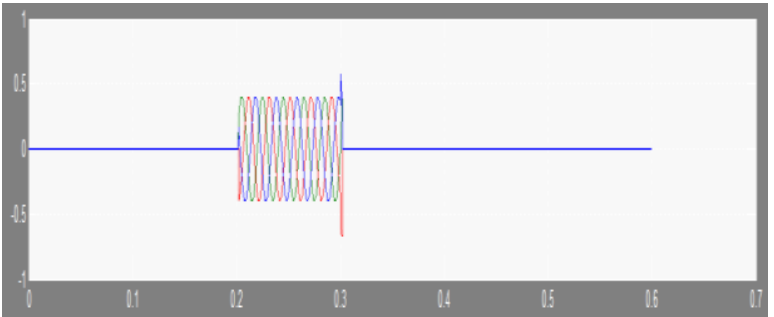

Figure 6(b): Compensated Voltage injected by DVR

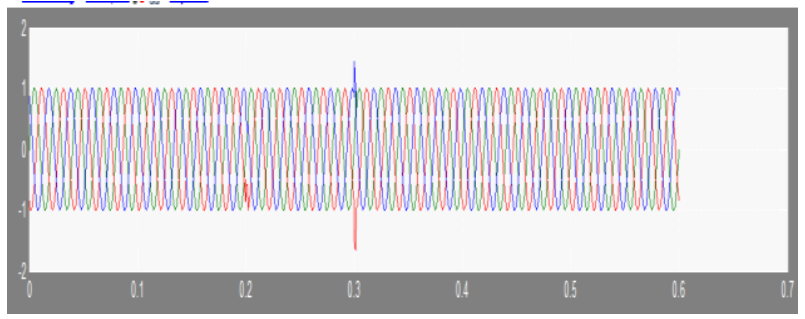

Figure 6(c): Load Side Voltage after clearing the Voltage Sag
Figure-6(a) shows 50\% voltage sag. Figure- 3(b) and (c) show the voltage injected by the DVR and the compensated load voltage, respectively. As a result of DVR, the load voltage is kept at 1 p.u. throughout the simulation, including the voltage sag period. It is observed that during normal operation, the DVR is not operational. It quickly injects necessary voltage components to smoothen the load voltage upon detecting voltage sag.

Figure-7(a) shows the transient performance of the system under voltage sag and swell conditions. Figure-7(b) shows the in-phase injection of voltage by the DVR. The load voltage is maintained sinusoidal by injecting proper compensation voltage by the DVR shown in Figure-7(c).

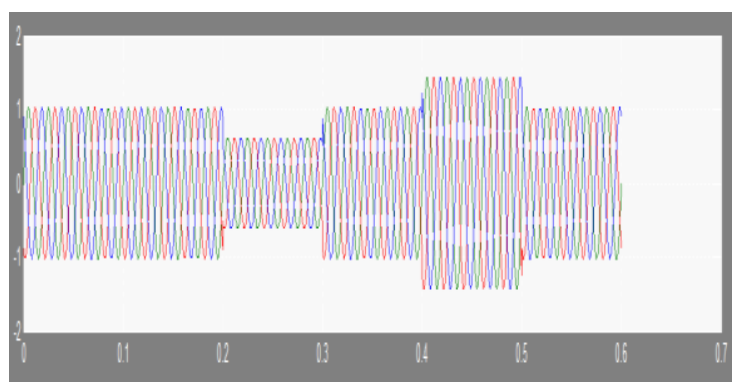

Figure 7(a): Supply Side Voltage with 50\% voltage Sag and $50 \%$ voltage Swell

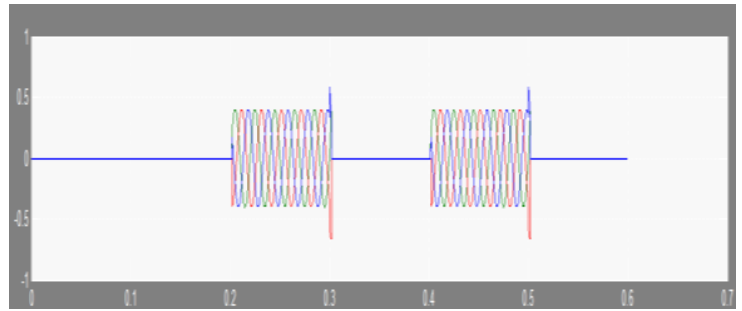

Figure 7(b): Compensated Voltage injected by DVR for compensating voltage

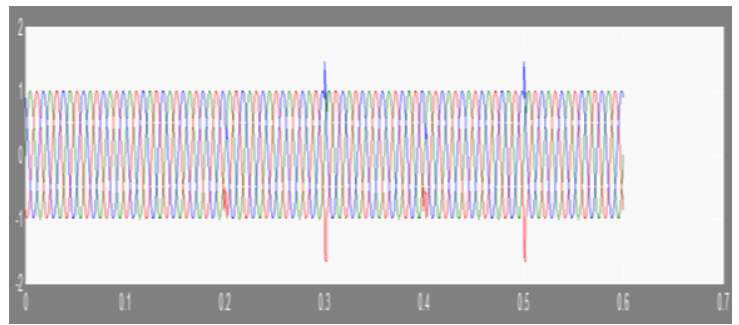

Figure 7(c): Load Side Voltage after clearing the Voltage Sag and swell

The Harmonic compensation is shown in the Figure 8(a),8(b).

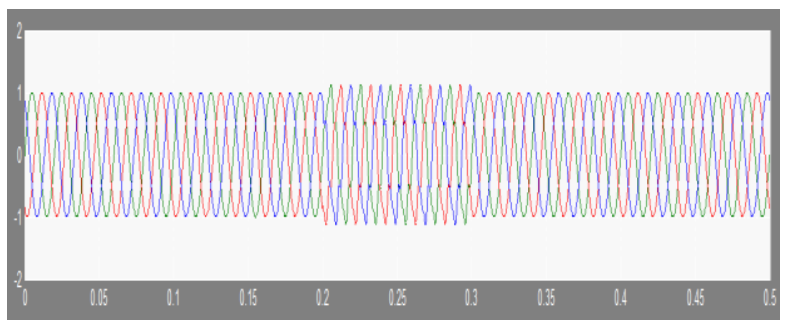

Figure 8(a): Supply Side Voltage adding with Harmonics 




Figure 8(b): Load Side Voltage after Harmonics compensation

By doing the FFT analysis the harmonic distortion value can be determined.The harmonic distortion is reduced in the load side when compared to the harmonic distortion in the source side.FFT analysis graph is shown in Figure 9(a), 9 (b).

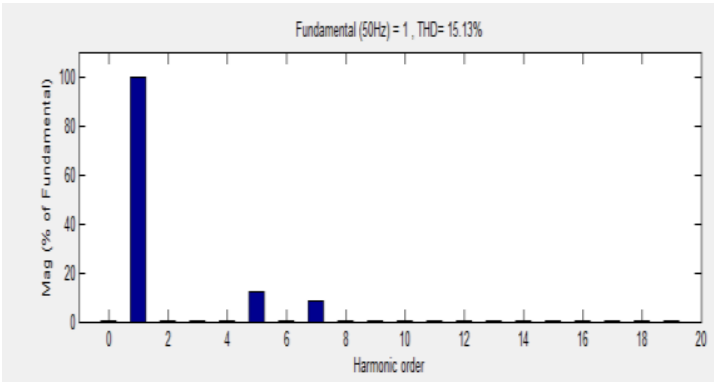

Figure 9(a):FFT analysis at source side

Here the graph is drawn between Frequency and Magnitude.The Harmonic Distortion at the source side is $15.13 \%$.

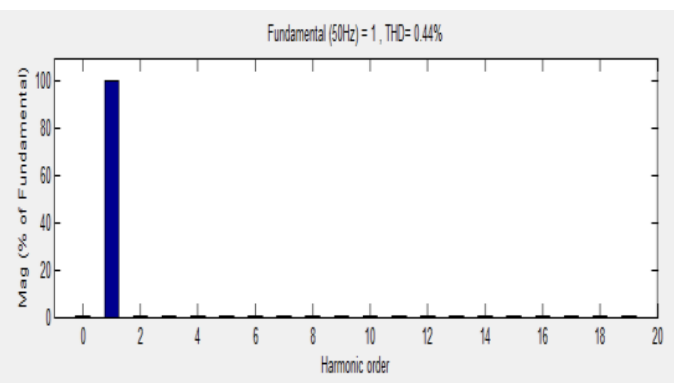

Figure 9(b):FFT analysis at load side

The Harmonic Distortion at load side is $0.44 \%$.This means harmonic distortion is reduced in the load side when compared to the source side which is desirable feature.

Appendix:

AC line voltage: $415 \mathrm{~V}, 50 \mathrm{~Hz}$ Load: $10 \mathrm{KVA}, 0.80 \mathrm{pf}$ lag PI Controller: $\mathrm{Kp}=5 \mathrm{Ki}=120 \mathrm{DC}$ voltage of DVR: $300 \mathrm{~V}$ Harmonic Filter: $\mathrm{Lr}=2.0 \mathrm{mH}, \mathrm{Cr}=10 \mu \mathrm{F}, \mathrm{Rr}=4.8 \Omega \mathrm{PWM}$ Switching Frequency: $1080 \mathrm{~Hz}$ Injection Transformer:Turns Ratio $=1: 1$ Inverter: IGBT based 3 arms, 6 Pulse, Frequency $=1080 \mathrm{~Hz}$, Sample Time $=5 \mu \mathrm{s}$ DC Bus Capacitance of DVR: $1000 \mu \mathrm{F}$

\section{CONTROL OF DYNAMIC VOLTAGE RESTORER USING MATLAB CODE}

In the above described system control unit of Dynamic Voltage Restorer is designed with the help of Simulink blocks.But the Control unit can also designed by matlab
coding.Generally Dynamic Voltage Restorer is made of Power electronic devices.To switch on the Power electronic devices pulses is required.Pulses are generated from Control unit. When the Control unit generated the pulses the pulses are given to the power electronic devices which are present in the Dynamic Voltage Restrorer.So the generation of pulses in the Control unit is designed by Matlab coding.



Figure 10: Subsystem in Control unit which generates pulses

In the above figure Pulse Width Modulation is placed.For the PWM generator there are four inputs and six outputs.The six outputs are given to the Mux as input.The Mux generates the single output.These output is nothing but pulses.So the generated pulses is given to the power electronic devices which are present in the Dynamic Voltage Restorer.

When the Matlab coding is placed in the subsystem of the Control unit in DVR,the Performance of DVR is as follows



Figure 11(a):FFT analysis at Source side by using Matlab coding

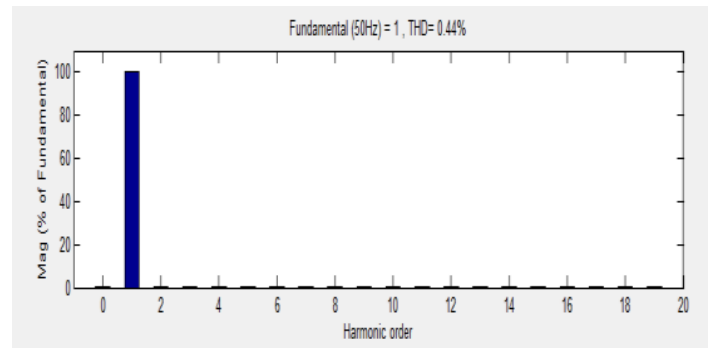

Figure 11(b):FFT analysis at load side by using Matlab coding

Total Harmonic Distortion at source side is $15.13 \%$ whereas at the load side is $0.44 \%$. This shows that the harmonics are reduced from source side to load side.

\section{CONCLUSION}

The study of DVR is focused on applying a new a new compensating voltage generation method. Generally 
harmonics are present in source side such that output at the load side is distorted. In this paper DVR is proposed. By placing the DVR harmonics can be reduced in load side .Voltage sag and swell can also be reduced by using DVR.DVR injects the compensated voltage. when this compensated voltage gets combined with source voltage then required load voltage is obtained with reduced harmonics. Figure 6(a) shows the $50 \%$ of voltage sag, Figure 6(b) shows compensated voltage injected by DVR ,Figure 6(c) shows load voltage clearing voltage sag. Figure 7(a) shows the $50 \%$ of voltage sag and $50 \%$ of voltage swell, Figure 7(b) shows compensated voltage injected by DVR, Figure 7(c) shows load voltage clearing voltage sag and voltage swell. The controller is able to detect different types of power quality problems without an error and injects the appropriate voltage component to correct immediately any abnormality in the terminal voltage to keep the load voltage balanced and constant at the nominal value. Simulation and experimental results show that, the proposed DVR successfully protects the most critical load against voltage sags. Here in this paper DVR Control unit is executed by using Matlab Simulation and Matlab coding. The results of Simulation and Coding are same. Figures 9(a), 9(b) shows the Simulation results whereas figures 11(a), 11(b) shows the Coding results. The above represented figures shows the same result.

\section{REFERENCES}

[1] M.Sharanya, B.Basavaraja , M.Sasikala "An Overview of Dynamic Voltage Restorer for Voltage Profile Improvement" (IJEAT) ISSN: 2249 - 8958, Volume-2, Issue-2, December 2012.

[2] Kapil P. Radadiya, Dr. Chirag K. Vibhakar, Sachin V. Rajani and Kishan J. Bhayani " Voltage Sag/Swell Compensation Using Dynamic Voltage Restorer (DVR)" (IJAIEM) ISSN 2319 - 4847 Special Issue for National Conference On Recent Advances in Technology and Management for Integrated Growth 2013 (RATMIG 2013)

[3] Ms.S.P.Awate "Enhancement of Voltage Profile Using Dynamic Voltage Restorer" IJAREEIE Vol 2,issue 12, December 2013

[4] Anita Pakharia,Manoj Gupta "Dyanamic Voltage Restorer for Compensation of Voltage Sag and Swell: A Literature Review" IJAET ISSN: 2231-1963 July 2012.

[5] Chellali BENACHAIBA, Brahim FERDI "Voltage Quality Improvement Using DVR" Electrical Power Quality and Utilisation, Journal Vol. XIV, No. 1, 2008

[6] Mr.Subhro Paul, Pradip Kumar Saha, Gautam Kumar Panda "Power QualityImprovement Using New Control Algorithm Based Dynamic Voltage Restorer" IJAREEIE ISSN 2278-8875 vol 1,issue 3,September 2012. 